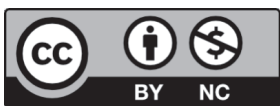

\title{
APOIO ESPIRITUAL A FAMÍLIAS QUE VIVENCIAM A EXPERIÊNCIA DO DIVÓRCIO
}

\section{Spiritual support to families that live the experience of divorce}

\section{Flávia Diniz Roldão}

Teóloga, pedagoga, Mestre em Psicologia pela Universidade Federal do Paraná (UFPR), especialista em Arteterapia pelo ISEPE e em Fundamentos do Ensino das Artes pela FAP, aperfeiçoamento em Saúde Mental, professora da Faculdade Evangélica do Paraná, Curitiba, PR - Brasil, e-mail: aquarelavirtual@hotmail.com

\section{Resumo}

O trabalho faz uma reflexão teórica sobre a intervenção de ajuda e apoio espiritual a famílias que enfrentam a difícil transição do divórcio em seu ciclo vital. Aborda essa questão fazendo dialogar Psicologia e Teologia. O processo de divórcio implica diferentes tipos de perdas para as diferentes famílias e para as diferentes pessoas que fazem parte do sistema familiar. Toda perda impõe a necessidade de realização de processos de luto pelas mesmas, a fim de que o sistema possa lamentar as suas perdas, se reorganizar, e tocar a vida adiante com novos projetos. $\mathrm{O}$ apoio espiritual que pode ser prestado às famílias que vivenciam essa experiência de sofrimentos pelo processo de divórcio pode ser uma estratégia efetiva que sinalize possibilidades de acolhimento, esperança e transformação de 
sofrimentos e prantos em novas possibilidades. Destacam-se cinco diretrizes de ação para o apoio espiritual das famílias nesses casos: a) Agir com compaixão e acolher aqueles que sofrem; b) Relembrar Jesus como aquele que sacia e pode auxiliar a superar o vazio da perda; c) Auxiliar na lida com emoções dolorosas e difíceis que emergem na experiência de luto, sem negá-las, escondê-las ou banalizá-las; d) Auxiliar as pessoas a manterem os olhos voltados para a "boa nova"do Evangelho de Cristo, mantendo acesa a esperança; e) Oferecer à pessoa e à família a oportunidade de perceber que Deus pode transformar seus prantos em novas possibilidades.

Palavras-chave: Divórcio. Aconselhamento. Apoio espiritual. Teologia prática.

\section{Abstract}

This work makes a theoretical reflection about the intervention of help and spiritual support to families that face the difficult transition of the divorce in their vital cycle. It approaches this issue making a dialogue between Psychology and Theology. The process of the divorce implicates different types of losses for the different families, and for the different people that are part of the family system. Every loss imposes the need of accomplishing mourning processes in order for the system to lament its losses, get reorganized and continue living new projects. The spiritual support that can be given to the families that live this experience of sufferings for the divorce process can be an effective strategy that signs for the possibility of reception, hope and transformation of sufferings and weeping in new possibilities. There are five action guidelines for spiritual support of families that stand out in these cases: a) Acting with compassion and receiving those that suffer; b) Remembering Jesus as the one who satiates and can help to overcome the emptiness of the loss; c) Helping to handle the painful and difficult emotions that emerge in the experience in mourning, without denying, hiding or vulgarizing them; d) Helping people to focus on the "good news" of the Gospel, maintaining this hope 
lit; e) Offering the person and the family the opportunity to notice that God can transform their weeping into new possibilities.

Keywords: Divorce. Counseling. Spiritual support. Practical theology.

\section{INTRODUÇÃO}

Perder suga a gente. ${ }^{1}$

O trabalho faz uma reflexão teórica sobre a intervenção de ajuda e apoio espiritual a famílias que enfrentam a difícil transição do divórcio em seu ciclo vital. Aborda essa questão fazendo dialogar Psicologia e Teologia.

Ao buscar atender e cuidar de uma família ou uma pessoa que está passando por essa experiência, deve-se buscar compreendê-las na sua totalidade constitutiva, sem fragmentá-las cuidando apenas de um ou outro aspecto de seu ser. Entretanto, o cuidado espiritual das pessoas que passam pela experiência do divórcio tem sido pouco tematizado em publicações científicas. Contudo, é impossível falar da dolorosa experiência do divórcio sem buscar compreender as implicações sobre os processos psicológicos pessoais e familiares nela envolvidos. Essa compreensão é importante a fim de que o apoio espiritual possa ser adequadamente oferecido como uma contribuição de boa qualidade no enfrentamento saudável desse processo, cuidando para que, através de uma ação interventiva de ajuda e apoio, não se aumente o sofrimento daqueles que naturalmente já sofrem (causando efeitos iatrogênicos). Afinal, a experiência de divórcio é uma experiência de perda, e como tal, implica subsequente e doloroso processo momentâneo de desorganização pessoal e luto, pelas múltiplas perdas que ele acarreta.

O processo de apoio espiritual que pode ser prestado no auxílio à superação da desorganização pessoal momentânea, e do luto, para que esse se efetive de um modo saudável e menos sofrido, é o que pretendemos enfocar aqui. Afinal, como afirma Saunders apud Pessini e Drane (2005, p. 228.), “o sofrimento humano somente é intolerável quando ninguém cuida".

1 Comentário filosófico de um garoto de 8 anos sobre a perda, citado por Viorst (1988, p. 14-15).

Rev. Pistis Prax., Teol. Pastor., Curitiba, v. 2, n. 1, p. 173-191, jan./jun. 2010 


\title{
A dimensão psicológica da perda no divórcio
}

\author{
ADEUS \\ Fui-me da vida tanto inverno tanta sombra \\ Há muito que sonhava um sol que não morresse \\ [...] \\ Morriam canções na voz da passarada \\ Tudo o que era belo se fazia em nada \\ Fechavam-se os lábios que tinham sorrido \\ [...] \\ Guardava comigo que bem me recordo \\ No final das noites no final dos dias \\ Minhas mãos vazias minhas mãos vazias
}

Sonhava há muito um sol que não morresse

(GERALDO, 2009)

Das dimensões que constituem o humano, a psicológica merece atenção especial durante os processos de separação conjugal e divórcio, pois o impacto desse processo, embora possa não ser fatal para os envolvidos, marca a vida das pessoas de um modo permanente. ${ }^{2}$ Brito (2005, p. 29) assim define o divórcio:

Divórcio é rompimento, é separação, é quebra de sonhos e esperanças, é o fim de vários projetos feitos em conjunto por um grupo familiar. Para um dos membros da família divorciada pode até ser alívio no seu momento presente, ainda assim, constitui-se um evento trágico na história da família.

Conforme a Escala de Avaliação do Reajustamento Social de Holmes e Rahe (apud CLINEBELL, 1987, p. 183), professores de psiquiatria da Universidade de Washington, que medem o estresse relativo vivenciado pelas

2 Segundo WALSH, 2005, o impacto de uma perda sobre a família pode reverberar imediatamente ou muito tempo depois.

Rev. Pistis Prax., Teol. Pastor., Curitiba, v. 2, n. 1, p. 173-191, jan./jun. 2010 
pessoas em diferentes situações, uma experiência de divórcio é a segunda experiência de maior impacto estressante na vida de uma pessoa. Marcando 73 pontos, e perdendo apenas para a morte de um cônjuge, que soma 100 pontos. A experiência do divórcio é seguida nessa escala pela experiência de separação marital do/a companheiro/a, com 65 pontos, que fica em terceiro lugar no lista de experiências estressoras. Como se pode perceber, a perda de um(a) companheiro(a) por separação e a experiência do divórcio podem ser devastadoras.

$\mathrm{Na}$ maioria das vezes, quando duas pessoas se "encontram" e estabelecem uma relação de casal, elas constroem juntas projetos de vida. Nos casos de separação, tem-se o rompimento de projetos conjuntos sobre os quais o casal debruçou-se e investiu tempo e energia, mas cujo sentido acabou desvanecendo e tornando-se sem um significado forte o suficiente que implicasse contínuo investimento. Isso ocorre não sem sofrimento e estresse para uma ou para ambas as partes do casal. Cabe considerar ainda que o estresse tem influências sobre a dimensão física da pessoa: quando prolongado, causa modificações imunológicas e pode influenciar na patogênese de doenças (ALMEIDA, 2003; LIPP, 2003; NUNES, 2007; SAPOLSKY, 2006).

Pesquisa de Parkes (1998) em estudo com mulheres viúvas mostra que experiências de luto estão também relacionadas a uma maior predisposição ao adoecimento e à busca por um atendimento clínico. Mas conforme bem alerta Viorst (1988, p. 13-14):

[...] Perdemos, não só pela morte, mas também por abandonar e ser abandonado, por mudar e deixar coisas pra trás e seguir nosso caminho. E nossas perdas incluem não apenas separações e partidas dos que amamos, mas também a perda consciente ou inconsciente de sonhos românticos, expectativas impossíveis, ilusões de segurança - e a perda do nosso próprio eu jovem, o eu que se julgava para sempre imune às rugas, invulnerável, imortal.

Há muitas formas diferentes de perdas pelas quais pode passar um adulto e que levam ao necessário trabalho de luto; dentre elas está a experiência do divórcio, que é um tipo de perda que acarreta outras múltiplas perdas que variam de caso a caso. Conforme Caruso (1968/1989, p. 20) apud Feres-Carneiro (2003, p. 267), "estudar a separação amorosa significa estudar a presença da morte na vida..." Nesse sentido bem ressalta Brito (1992, p. 37): 
[...] Levando em conta que pode ser como a dor da perda pela morte. No caso do divórcio, a pessoa da qual se foi privada, ainda está viva e pode estar agora 'nos braços' de outra pessoa. Isso de fato pode ser terrível, pois o sentimento de perda é somado ao da rejeição.

Conforme Porchat (1992, p. 105) apud Brito (1992, p. 38):

No caso do vínculo marital simbiótico, no qual, o rompimento da relação pode equivaler à morte, a separação se torna tão angustiante para o casal simbiótico que, muitas vezes, ela pode levar ao suicídio de um deles, ou produzir atos de violência.

Diferente do que se costuma ouvir no senso comum, que por vezes transmite a ideia de que trocar de companheiro(a) pode ser como trocar de roupa - uma visão utilitarista e que vê a pessoa como um mero objeto a ser substituído -, a experiência de divórcio é uma experiência de separação, e como tal, envolve ruptura, desistir, abrir mão, e toda uma complexidade de processos relacionais, sociais e psicológicos aí implicados.

Pesquisa empreendida por Feres-Carneiro (2003) descreve o processo de separação como muito difícil e sofrido, e nas falas das mulheres o sentimento de desilusão, a vivência da mágoa e da solidão foram bastante destacados, enquanto os homens destacaram sentimentos de frustração e fracasso. Como é possível perceber, os sentimentos destacados não são sentimentos banais, mas profundos. Cabe então o destaque de que se isso for esquecido, a experiência de divórcio pode parecer uma experiência fútil, simples, e pode ser tratada sem se dar o devido cuidado e atenção às famílias que a atravessam, expressando na vida o que bem descreve o poema de Epanca (1999), “A minha dor”:

A minha dor é um convento ideal.

Cheio de claustros, sombras, arcarias [...]

Nesse triste convento aonde eu moro.

Noites e dias rezo e grito e choro!

E ninguém ouve... ninguém vê... ninguém...

A experiência do divórcio não se refere a um momento, mas é um processo, pois tal qual a experiência de vinculação, leva tempo e exige investimento afetivo. A separação é um processo complexo de desvinculação 
que também leva tempo, investimento, e exige o luto das perdas. A experiência da perda primária do(a) companheiro(a) no divórcio traz consigo outra perdas secundárias, com as quais cada pessoa da família deverá lidar. Mas é importante não esquecer que o ser humano só se enluta por aquilo que amou, por aquilo que teve e perdeu, por aquilo ao que se ligou e que depois se separou, por aquilo em que investiu. Enquanto processo, o luto envolve diferentes momentos que precisam ser vividos e superados para que as pessoas, depois de vivenciarem-no, possam tocar suas vidas adiante, reinvestindo em novos projetos de vida.

As perdas são experiências profundamente dolorosas, e a tendência de algumas pessoas diante dessas situações dolorosas é fugir, ou negá-las o quanto podem. Contudo, a perda precisa ser enfrentada quando a pessoa se vê face a face com um fato do qual não dá pra fugir e que não é possível negar. Nesse momento não há opções: é necessário fazer o enfrentamento para não ficar paralisado e poder tocar a vida vivendo, e não apenas sobrevivendo enquanto ainda há vida.

O divórcio foi conceituado por Carter e MacGoldrick (1995, p. 22) "como uma interrupção ou deslocamento do tradicional ciclo de vida familiar". Como toda interrupção e deslocamento, pode causar profundo sofrimento, sobretudo pelos sonhos não realizados. Não há um padrão comum de enfrentamento e de sintomas que podem advir dessa experiência. As pessoas e as situações que levam à separação são muito diversificadas, e assim, cada família tomada no seu conjunto, e cada pessoa individualmente, realiza o enfrentamento e manifesta suas próprias reações à separação à sua própria forma e conforme os seus próprios recursos e o seu momento histórico.

Algumas pessoas podem vivenciar essa experiência de modo muito parecido com aquelas que sofreram uma experiência de amputação. Na verdade há a ausência de uma parte que anteriormente estava presente na família, mas que foi embora, ou não está mais presente. Isso exige profunda reorganização pessoal e familiar envolvendo todos os integrantes da família. Para que essa reorganização possa ser realizada da melhor maneira possível, fortalecer a resiliência ${ }^{3}$ familiar (WALSH, 2005) torna-se um objetivo importante em toda relação de ajuda e apoio oferecidos.

3 Para Walsh (2005, p. 4), "resiliência pode ser definida como a capacidade de se renascer da adversidade fortalecido e com mais recursos. É um processo ativo de resistência, reestruturação e crescimento em resposta à crise e ao desafio."

Rev. Pistis Prax., Teol. Pastor., Curitiba, v. 2, n. 1, p. 173-191, jan./jun. 2010 
Se para aliviar a dor física do ser humano existem medicamentos, para o sofrimento, que tem uma dimensão imaterial, simbólica, psíquica, afetando a alma e o espírito, o medicamento de alívio é a organização e ressignificação das ideias pela fala e construção de novos significados. Assim, o diálogo com um interlocutor que se apresente disposto a uma escuta empática e sensível, usando o silêncio terapêutico quando necessário, para aqueles sofrimentos sobre os quais apenas o respeito da escuta pode ser o alívio da alma que sofre, pode ser remédio fundamental para a alma e o espírito.

Como escrevem Carter e MacGoldrick (1995, p. 23):

As emoções liberadas durante o processo de divórcio relacionam-se primariamente à elaboração do divórcio emocional - isto é, à recuperação do eu em relação ao casamento. Cada parceiro deve recuperar esperanças, sonhos, planos e expectativas que foram investidos nesse cônjuge e nesse casamento. Isso requer um luto por aquilo que foi perdido e o manejo da mágoa, raiva, culpa, vergonha e perda em si mesmo, no cônjuge, nos filhos e na família ampliada [...] As famílias em que as questões emocionais do divórcio não estão adequadamente resolvidas podem permanecer emocionalmente paralisadas por anos, se não por gerações.

Assim, é possível considerar as famílias que passam por essa experiência, mas que continuam se esforçando por tocarem suas vidas adiante salutarmente e envolvendo-se em novos projetos de vida, como famílias guerreiras. Apesar de uma experiência dolorosa precisar ter sido enfrentada ao longo de seu ciclo familiar vital, as pessoas continuam vivendo, e não apenas sobrevivendo, enquanto ainda há vida que nelas pulsa.

Todo casamento implica a organização de uma nova identidade, assim também em um processo de separação está colocada a difícil tarefa a ser realizada, a de uma nova configuração da identidade dos envolvidos principalmente dos antigos cônjuges. Conforme Feres-Carneiro (2003), "desconstruir a conjugalidade após a separação e, simultaneamente, reconstruir a identidade individual é um processo lento e vivenciado com dificuldade pelos ex-cônjuges". Mas o importante a ser destacado é que nesse processo de crise pelo qual passa a família no processo de divórcio, já que não há possibilidade de fugir ao enfrentamento da situação, essa deve ser enfrentada corajosamente. De acordo com Maria Tereza Maldonado (1985), nesse processo deve-se reconhecer que sempre há duas possibilidades implícitas nos momentos de 
crise: possibilidade ou estagnação, "perigo ou oportunidade", constituindo, como diz essa autora, "verdadeira encruzilhadas em termos de saúde mental" (MALDONADO, 1985, p. 20).

A família pode passar por esse momento difícil vivenciando-o como uma oportunidade para crescer apesar do sofrimento aí envolvido. Aliás, em situação de luto, as lágrimas são o bálsamo que cura. A família pode desejar intencionalmente aprender com essa experiência, com seus erros e acertos, a fim de construir um futuro diferente para todos os envolvidos.

Normalmente, esse é um momento complicado e carregado de sentimentos fortes e ambíguos, e os membros da família não conseguem encarar a situação dessa forma. Nesses casos cabe ao ajudador auxiliar nesse processo, sendo empático com o sofrimento profundo dos envolvidos, e ajudando-os a reconstruírem suas histórias de vida vislumbrando um futuro diferente. Mas como se pode imaginar, isso também exige do cuidador que vai oferecer o apoio nesse processo doloroso muita coragem de olhar a situação de frente como ela realmente é e encarar lidar com sofrimentos profundos, muita empatia e uma postura de acolhimento - tal qual o exemplo oferecido em muitas ocasiões por Jesus, conforme diversos relatos na Bíblia.

\section{O processo de luto}

Conforme Rupp (1996), o luto implica a realização de duas tarefas fundamentais:

1) A separação;

2) O aceite ao convite para o movimento como forma de crescer.

Para crescer, alerta Viorst (1988, p. 14), é preciso às vezes: desistir e deixar coisas pra trás. É preciso abrir mão, realizar adaptações, e abrir-se a mudanças. Viver no passado não ajuda. Abrir mão de sonhos não realizados pode ser muito importante.

O processo de luto é um processo de passagem. Ele é o processo de transição entre uma realidade que não existe mais e outra que ainda não foi estabelecida: um período em que, figuradamente falando, se está no lodo, ou no vazio. Mas esse pode ser um vazio fértil, pois é a partir do não-ser que as 
coisas novas podem surgir. Vaugham (1991, p. 60) assim escreve sobre esse processo: "A separação é mais do que um abandono. Também é uma transição para uma vida diferente. Ela é marcada pela coincidência entre partir e chegar, ou seja, a mistura entre sair de um lugar e entrar em outro."

É nesse período em que o novo ainda não surgiu, e que há sofrimento por alguém ou algo que partiu, que se pode exercitar o que o teólogo e psicanalista Rollo May chamou de "a coragem de criar". Coragem, para Kierkegaard, Camus e Sartre, "não é a ausência do desespero, mas a capacidade de seguir em frente, apesar do desespero", escreve May (1975, p. 10). E continua: "[...] a arte criativa nos permite alcançar além da morte" (MAY, 1975, p. 23).

A tarefa do luto é enfrentar a dor e o sofrimento colocados pelo desafio da separação e prosseguir adiante corajosamente, criando novos rumos e projetos que dêem novos significados ou retomem antigos significados para a vida, e que possibilitem ao ser humano viver efetivamente, enquanto nele há o sopro de vida. É preciso que o cuidador ${ }^{4}$ possa auxiliar a pessoa a abordar o luto de um ponto de vista construtivo e generativo de novos significados para a vida.

Parkes (1998) destacou cinco fases no processo de luto por morte:

1) Entorpecimento;

2) Saudade ou procura pelo outro;

3) Desorganização;

4) Desespero;

5) Recuperação.

Como é possível observar, vivenciar cada um desses momentos exige muita coragem e esforço para seguir adiante e superar o processo. Apesar de essas fases estabelecidas referirem-se ao processo de luto por morte, o luto pela perda da separação e divórcio pode ser vivenciado como um processo bastante semelhante. Worden (1998) postula quatro tarefas do processo de luto pela morte:

1) Aceitar a realidade da perda;

2) Elaborar a dor da perda;

3) Ajustar-se a um ambiente onde está faltando a pessoa que faleceu;

4 Aquele que vai oferecer o apoio espiritual. 
4) Reposicionar em termos emocionais a pessoa que faleceu e continuar a vida.

Também aqui essas tarefas podem ser vividas de um modo bastante semelhante nos casos de perda pela separação e divórcio, mas vale salientar que quanto a essa última tarefa, no caso do divórcio há um complicador maior: as pessoas ainda estão vivas, apesar de separadas conjugalmente. No caso do casal ter tido filhos, o vínculo conjugal se desfaz, mas o vínculo parental ainda permanece - e, para o bem da prole, uma boa relação deve ser buscada entre os ex-cônjuges. Considerar isso na "re-posição", em termos emocionais, que vai ser assumida em relação ao ex-cônjuge, primando pelo respeito ao outro e a consideração mútua, é algo fundamental.

Vivenciar um processo de luto sempre causa desconforto. Contudo, as pessoas e as famílias, enquanto sistema, precisam suportá-lo e enfrentá-lo corajosamente, até que tenham digerido as emoções envolvidas, e elaborado as questões que emergiram no processo de separação. $O$ evento necessita ser integrado à sua história de vida, sem que a pessoa e a família neguem que ele ocorreu e nem as suas consequências sobre a vida, mas que possam afirmar a necessidade de reorganizar a vida de um modo mais adequado a esse novo momento histórico que estão vivenciando.

Uma perda causa reverberações (em curto e longo prazo) sobre todos os membros da família, ocorre uma onda de choque, e esse fato tem influências sobre todos os demais relacionamentos que esses membros estabelecerão durante o resto de suas vidas (WALSH, 2005). Por isso, elaborar e integrar esse evento difícil na história de vida é muito importante.

Elaborar o processo de luto, no caso da experiência de divórcio, significa chorar as perdas e reestruturar o sistema familiar, já que as perdas que ocorrem da separação modificam a estrutura da família, e os antigos padrões exibidos anteriormente tornam-se pouco adaptativos diante da nova realidade que se apresenta. Toda mudança é um desafio, pois implica abrir-se para o novo e desconhecido, podendo causar medo e ansiedade. Mas realizar o enfrentamento do medo e lidar com a ansiedade presente nesse processo é parte do processo de elaboração e crescimento de cada pessoa e da família como um sistema. Contudo, cada pessoa tem o seu jeito próprio e o seu próprio ritmo de enfrentamento dessa difícil realidade. 
No enfrentamento desse doloroso processo os membros podem servir de apoio uns aos outros, e, nesse sentido, a família pode sair desse processo de luto muito mais amadurecida e tendo seus vínculos fortalecidos, se puder lidar sabiamente com a situação que se apresenta. É nesse sentido que Walsh (2005), ao falar de processos de resiliência familiar, destaca a importância fundamental dos processos de comunicação para o seu desenvolvimento. Para essa autora, concentrar-se em como as famílias podem ter sucesso é o alvo importante. Ela escreve:

Uma abordagem da resiliência familiar visa identificar e fortalecer processos interacionais fundamentais que permitem às famílias resistir aos desafios desorganizadores da vida e renascer a partir deles. Uma lente da resiliência familiar muda a perspectiva de se encarar as famílias em situações de angústia como defeituosas, para encará-las como desafiadas, ratificando o seu potencial para o reparo e o crescimento. Essa abordagem baseia-se na convicção de que tanto a força individual quanto a força familiar podem ser forjadas por esforços cooperativos para lidar com a crise repentina ou com a adversidade prolongada. [...] Em vez de nos concentrarmos em como as famílias fracassaram, podemos dirigir nossa atenção para como elas podem ter sucesso (WALSH, 2005 p. 3-4, grifos meus).

Abordar o potencial que as famílias têm, ao invés do fracasso, destacar a possibilidade de buscar a alegria e encontrar superação para a dor, e concentrar-se nas possibilidades de um futuro renovado, ao invés de focar no passado de sofrimento, podem ser estratégias utilizadas para auxiliar na superação do luto.

Se lembrarmos de Jesus veremos que ele jamais apagava a esperança das pessoas com as quais se encontrava em seu caminho aqui na Terra, mas ele as convidava para uma mudança através da "boa nova" que ele pregava, e do evangelho que vivenciava em sua própria vida. Diante das experiências de morte nesta vida, é importante lembrar da possibilidade de ressurreição após a morte, e da beleza da páscoa.

O enfrentamento de sentimentos e sonhos que morreram no adoecedor processo de uma separação, quando enfrentados sob a esperança iluminadora da boa nova trazida pelo Cristo, faz lembrar da possibilidade de renascer a vida, apesar dos erros e imaturidades que se possa ter vivenciado

Rev. Pistis Prax., Teol. Pastor., Curitiba, v. 2, n. 1, p. 173-191, jan./jun. 2010 
em um tempo passado. Para o evangelho da boa nova e vida pelna, sempre poderá haver um novo e renovado amanhã, tal qual foi para Zaqueu o ladrão, ou para a mulher adúltera, e para os homicidas Davi e Moisés, ou Jonas, o medroso, fujão.

\section{Oferecendo apoio espiritual na experiência de luto pela vivência de um divórcio: uma perspectiva cristã}

O conceito de espiritualidade está ligado àquilo que faz as pessoas serem melhores (BOFF, 2001), que as ajuda a dar um significado profundo à existência, àquilo que as conecta com o transcendente, com aquele que é onisciente, onipotente e onipresente, sendo o alfa e o ômega: Deus - numa perspectiva cristã.

Oferecer apoio espiritual diante do anteriormente exposto chama o cuidador para atuar alguns conceitos e comportamentos adequados à perspectiva da filosofia e fé cristã. Abordaremos a seguir alguns deles.

\section{a. Agir com compaixão e acolher aqueles que sofrem}

"... e compadeceu-se deles, porque eram como ovelhas que não têm pastor..." (Mc 6,34b)

Compaixão e acolhimento foram características que marcaram o ministério de Jesus e suas relações com vários personagens bíblicos, como, por exemplo, no encontro com a mulher adúltera (Jo 8,1-11) prestes a ser apedrejada, e com a samaritana na beira do poço (Jo 4,1-30, especialmente o versículo 9, que mostra a atenção e a iniciativa de Jesus em dirigir-se a essa mulher). Também em seus ensinos, Jesus salientou o valor fundamental dado à compaixão em sua mensagem de amor e acolhida aos seres humanos, conforme destacado no texto de Mt 25,31-46.

Conforme Boff (2000, p. 9), a situação do contexto atual, marcado por profunda "falta de solidariedade e cuidado entre os seres humanos evoca a compaixão como uma realidade relevante e urgente". Lembrando as ideias de Tomás de Aquino, esse teólogo salienta que a compaixão é uma "característica essencial da Divindade" (BOFF, 2000, p. 10). 


\section{b. Relembrar Jesus como aquele que sacia e pode auxiliar a superar o vazio da perda}

Eu sou o pão da vida, o que vem a mim jamais terá fome; e o que crê em mim jamais terá sede. (Jo 6,35)

A experiência do divórcio pode lembrar aos envolvidos a experiência do deserto. $\mathrm{O}$ deserto é local de dificuldades e grandes desafios, e por vezes profunda solidão e questionamentos de toda espécie diante do sofrimento que ele causa, e o silêncio que se faz presente ali. Leloup (1998, p. 10), ao falar do deserto das relações, assim se expressa:

Há silêncios pesados, silêncios que não têm fim: o deserto está entre nós... A distância que nos separa parece intransponível; não adianta gritar nem explicar, ninguém nos responde. Estamos, no entanto, sentados à mesma mesa. Todavia, não existe mais comunhão. Dormimos na mesma cama, mas não dormimos mais nos mesmos sonhos; e cada manhã, colados um ao outro, nos encontramos cada vez mais afastados... Entre nós há o deserto, e não é mais o belo silêncio de nossas noites estreladas, mas o frio, a ausência à flor da pele.

A experiência do deserto na tradição cristã é uma experiência de falta, procura e busca. Também é assim com aqueles que estão passando pelos "desertos" da vida. Contudo, Jesus apresenta-se ao mundo como o "pão da vida", aquele que sacia a fome e a sede de espírito (Jo 6,35) que habita o humano e ajuda a superar o que lhe causa angústia. Só mesmo em sua onipotência pode oferecer esperança que transcende as forças humanas, apontando para a possibilidade do humano sentir-se profundamente apoiado nos momentos difíceis por que passa, para que possa superá-los, mantendo acesa a sua esperança de renascer para uma nova experiência de vida.

\section{c. Auxiliar na lida com emoções dolorosas e difíceis que emergem na experiência de luto, sem negá-las, escondê-las ou camuflá-las}

O Senhor é a minha luz e a minha salvação... (S1 27,1a) 
Emoção é energia. Ela não vai embora simplesmente por que uma pessoa resolve negar a sua existência ou fingir que ela não existe. Se ela existe está presente, e simplesmente não some pelo fato de ser ignorada. É preciso poder ajudar as pessoas a serem honestas com suas emoções, reconhecendo-as e lidando com elas. Mas o ajudador deve ter em mente, entretanto, que esse quase sempre é um processo muito difícil para elas. Por isso elas negam, ou fogem delas a todo o custo.

Aqui parece interessante lembrar um personagem bíblico que é conhecido como o personagem fujão: Jonas. Jonas tinha uma missão que era considerada para si como tão difícil de ser enfrentada que ele foge... E por mais absurdo que pareça, ele dorme calma e tranquilamente diante de uma situação caótica, na qual de algum modo ele mesmo tinha alguma participação. Em Jonas 1,3, lemos que esse profeta "pagou a sua passagem para fugir da rota de sua missão" e depois uma grande tempestade atingiu o barco em que ele se encontrava. Os marinheiros todos estavam com grande medo, mas ele, Jonas, dormia profundamente no porão.

Como esse profeta de Deus, por vezes aqueles que têm uma missão que para si parece muito difícil e dolorosa, tal qual a experiência de luto, fogem (consciente ou inconscientemente) da empreitada. Cabe ao ajudador se perguntar: estou apto e disposto a ajudar as pessoas a vivenciarem suas fortes emoções, tais como a raiva, por exemplo, sem impor culpa, aumentando o sofrimento, mas as ajudando a colocarem tudo nas mãos de Deus?

\section{d. Auxiliar as pessoas a manterem os olhos voltados para a "boa nova" do Evangelho de Cristo, mantendo acesa a esperança}

Eu vim para que tenham vida e a tenham em abundância. (Jo 10,10)

Quando, em Jo 10,10, o Cristo resume a sua missão e a boa notícia que Ele veio trazer a "todo" ser humano, Ele ensina o caminho para a superação de todos os problemas humanos: confiar na novidade que Ele traz ao mundo e dela desfrutar: a vida plena.

Essa boa notícia é a esperança para todas as pessoas que confiam em Deus e Nele colocam a sua confiança. Inclusive para aqueles cujos sonhos pessoais e conjugais foram impossíveis de ser vividos, e cujas vidas podem estar vindo de um processo subjetivo de devastação daí advindo. 


\title{
e. Oferecer à pessoa e à família a oportunidade de perceber que Deus pode transformar seus prantos em dança
}

\author{
Tornaste o meu pranto em folguedo; \\ desataste o meu pano de saco, \\ e me cingiste de alegria. (S1 30,11)
}

Tal como se lê no S1 30,11, em que se fala de Deus transformando pranto em dança, o teólogo Henri Nowen (2007), a partir de uma perspectiva cristã, destaca cinco passos através dos quais se pode sobreviver à dor e redescobrir a felicidade, e que bem podem ajudar a iluminar as ideias acerca do tema aqui proposto. São os seguintes os passos por ele propostos:

1) Fazer da situação de sofrimento uma ocasião para o crescimento, a partir de um enfrentamento real da dor ou daquilo que nos fere, e depositar nossas feridas em mãos maiores, praticando gratidão por tudo o que tivemos a oportunidade de viver, integrando em nossa história de vida mesmo os momentos mais dolorosos dela;

2) Saber soltar, deixar as coisas às quais nos agarramos compulsivamente, entendendo que as liberando, liberamo-nos a nós mesmos. É preciso aprender ainda a correr o risco de amar e permitir que coisas novas aconteçam. Aprender a amar inclusive a Deus, que nos permite lamentar - de modo verdadeiro - em sua presença. Deixar que Ele se manifeste de forma nova a nós. Isso é confrontar o medo dos espaços vazios, e criar em nosso coração um espaço onde se possa ouvir, tornar-se sensível e receptível a Deus;

3) Passar do fatalismo do "Não dá... Não consigo... Não tem jeito" para a esperança, sabendo que novas possibilidades "nos aguardam depois da curva". Através da confiança em Deus, integrar suas memórias à totalidade de sua história de vida, abrindo-se para novas expectativas de futuro;

4) Passar da manipulação ao amor; 
5) Passar da morte temível para a vida de gozo. Sempre estamos morrendo em diferentes sentidos todos os dias. O próprio Cristo uma vez alertou que se o grão de trigo não morrer não pode dar fruto (Jo 12,24). O passado de morte precisa ser deixado pra trás depois de apresentado na presença do Cristo, aquele que tudo perdoa, cura e restaura.

\section{CONCLUSÃO}

Neste trabalho buscou-se sensibilizar o leitor para perceber o divórcio como uma experiência complexa e difícil de ser enfrentada para as pessoas envolvidas, e para as famílias como uma unidade sistêmica. A superação da experiência do divórcio passa pela realização do lutos pelas diversas perdas nela implicadas. Pode-se prestar auxílio às pessoas da família nesse processo, intervindo através da oferta de apoio espiritual, mas quem pretende ajudar essas famílias necessita colocar-se empaticamente diante desse processo de ajuda. O respeito e a atenção qualificada são ferramentas fundamentais de trabalho a serem utilizadas por aqueles que desejam auxiliar nesse processo de passagem entre uma realidade anterior e a novidade que ainda não existe durante o enlutamento. A experiência de sofrimento causada pelo divórcio pode paralisar subjetivamente vidas e famílias, assim, a oferta de apoio psicológico e espiritual aos que vivenciam essa experiência de sofrimento pode auxiliar em seu enfrentamento e superação.

\section{REFERÊNCIAS}

ALMEIDA, O. M. M. S. A resposta neurofisiológica ao stress. In: LIPP, M. E. N. (Org.). Mecanismos neuropsicofisiológicos do stress: teoria e aplicações clínicas. São Paulo: Casa do Psicólogo, 2003. p. 25-30.

BOOF, L. Princípio de compaixão e cuidado. Petrópolis: Vozes, 2000. Espiritualidade: um caminho de transformação. São Paulo: Sextante, 2001. 
BRITO, E. P. Interação dos ritos e símbolos cristãos com a Terapia Narrativa no acompanhamento pastoral da família recasada. 2005. $251 \mathrm{f}$. Tese (Doutorado em Teologia) - Escola Superior de Teologia Instituto Ecumênico de Pós-Graduação, São Leopoldo, RS, 2005.

CARTER, B.; MACGOLDRICK, M. As mudanças no ciclo de vida familiar: uma estrutura para a Terapia Familiar. In: WALSH, F.; MACGOLDRICK, M. As mudanças no ciclo de vida familiar. Porto Alegre: Artmed, 1995. p. 373-391.

CLINEBELL, H. J. Aconselhamento pastoral: modelo centrado em crescimento e libertação. São Paulo: Paulinas; São Leopoldo, RS: Sinodal, 1987.

DRANE, J. P. L. Bioética, medicina e tecnologia: desafios éticos na fronteira do conhecimento humano. São Paulo: Loyola; Centro Universitário São Camilo, 2005.

ESPANCA, F. A mensageira das violetas. Porto Alegre: L\&PM, 1999.

FÉRES-CARNEIRO, T. Separação: o doloroso processo de dissolução da conjugalidade. Estudos de Psicologia (Natal), v. 8, n. 3, p. 367-374, 2003.

GERALDO, P. J. Adeus. Disponível em: <http://cidadela.net/adeus.htm>. Acesso em: 06 jul. 2009.

LELOUP, J. Y. Deserto desertos. 3. ed. Petrópolis: Vozes, 1998.

LIPP, M. E. N. O modelo quadrifásico do stress. In: LIPP, M. E. N. (Org.). Mecanismos neuropsicofisiológicos do stress: teoria e aplicações clínicas. São Paulo: Casa do Psicólogo, 2003. p. 17-22.

MALDONADO, M. T. P. Psicologia da gravidez. 10. ed. Petrópolis: Vozes, 1985.

MAY, R. A coragem de criar. 10. ed. Rio de Janeiro: Nova Fronteira, 1975.

NOWEN, H. Transforma meu pranto em dança. Rio de Janeiro: Thomas Nelson, 2007.

NUNES, S. O. V. Psicoimunologia. In: CONGRESSO SUL-BRASILEIRO DE GERIATRIA E GERONTOLOGIA, 5., 2007, Curitiba. Anais... Curitiba: [s.n.], 2007. PARKES, C. M. Luto: estudos sobre a perda na vida adulta. 3. ed. São Paulo: 
Summus, 1998.

RUPP, J. Rituais de despedida: a espiritualidade da mudança. São Paulo: Loyola, 1996.

SAPOLSKY, R. Assumindo o controle do stress. Viver Mente e Cérebro: Edição Especial - Doenças do Cérebro, n. 5, p. 66-75, 2006.

VAUGHAN, D. A separação: momentos decisivos da vida em comum. Rio de Janeiro: Paz e Terra, 1991.

VIORST, J. Perdas necessárias. São Paulo: Melhoramentos, 1988.

WALSH, F. Fortalecendo a resiliência familiar. São Paulo: Roca, 2005.

WORDEN, J. W. Terapia do luto: um manual para o profissional de saúde mental. 2. ed. Porto Alegre: Artmed, 1998.

Recebido: 21/09/2009

Received: 09/21/2009

Aprovado: 30/10/2009

Approved: 10/30/2009 